\title{
MÜRGISE SABAGA KOMEEDID, RISKIJUTUD JA
} KOMMENTAARID INTERNETIS

\author{
Mare Kõiva
}

\begin{abstract}
TEESID: Kultuuri ja teaduse hübridiseerumise olukorras mõjutavad meedia ja teadlaste eksperthinnangud komeedi mõju ühiskonnale. Võrdlen artiklis kahe komeediga seotud pärimuse reflekteerumist ühiskonnas: 2009. aastal nähtavaks muutunud Lulini puhul iseloomustan erinevaid internetikommentaare, Halley komeediga seoses paanika põhjuseid, paanilist käitumist ja riskijutte.
\end{abstract}

MÄRKSÕNAD: Halley komeet, internetikommentaarid, komeedipaanika, komeet Lulin, maailmalõpp, riskijutud

Komeedid avastatakse tänapäeval kutseliste astronoomide poolt tükk aega enne seda, kui nad muutuvad palja silmaga nähtavaks või amatöörile kättesaadava teleskoobi kaudu vaadeldavaks. Siiski satuvad nad meediauudiste vahendusel avalikkuse tähelepanu alla juba enne taevas nähtavale ilmumist. Peaaegu iga komeedi puhul levib kohe teatavaks saamise kannul maailmalõpu-ja katastroofiennete laine. Meil on raske jälgida, mis juhtus ühiskonnas vara- ja keskajal, isegi uusaja kohta on allikad napid ja ühekülgsed. Seetõttu on raske hinnata, missugused ettekujutused, hirmud ja uskumused aktiveerusid ja kui mõjukad nad olid.

Üks harukordne võimalus heita pilk aegade tagusesse ühiskonda oli jaapani poisi Matasaburou detailsete komeedi liikumist kujutavate joonistega ja kogukonna igapäevaelu ning suhtumisi peegeldavate sissekannetega päevik aastast 1660 (vt Kõiva 2007; Renshaw \& Ihara 1996). Päevikumärkmeist ilmnes inimeste kasvav huvi otse komeedi ilmumise järel, järkjärgult erinevate seoste loomine varasemate sündmuste ja sabatähe vahel. Meenutati traagilisi juhtumeid, mis leidsid aset eelmiste sabatähtede ilmumiste ajal, samas olid arvamused ja uskumused eriilmelised ja erihäälsed: nõustuti riski- ja katastroofivõimalusega, osa inimesi suhtus en- 
nustustesse huumoriga, osa eitas seost ja meenutas, et komeedi ilmumise ja ühiskondlike sündmuste vahel seos puudus.

Tänu internetifoorumitele on kunagi valdavalt suulises suhtlemises leviv uskumustik tänasel päeval kirjalikult jäädvustatud, sellele lisatud kommentaarid avavad konteksti. Ka on sama sündmus jälgitav samaaegselt eri kogukondades ja laiemal geograafilisel alal ning võimaldab vaadelda isiklikke narratiivseid uskumusliine, usundilisi hoiakuid ja neist moodustuvat mõttelist tervikut.

Käesolevas kirjutises vaatlen tavauskumusi ja kommentaare seoses komeet Luliniga, et iseloomustada, missuguseid vajadusi täidab komeedifolkloor tänases ühiskonnas. Perioodiliselt taasilmuv Halley komeet on kaunis ja tähelepanuväärne nähtus, mis on vähemalt korra olnud riskijuttude ja paanika põhjustaja. Lulin on kahtlemata tähtsusetu taevanähtus, mida ilma meedia ja teadlaste vahenduseta poleks märgatudki. Internetis jäädvustatud uskumuste ja arutluskäikude vahendusel saab ilmsiks, miks paljale silmale vähemärgatav nähtus verbaliseeritakse - see äratab emotsioone ja paneb mõtlema tuleviku üle.

Riskinarratiivide uurija Gaspar Mairal osutab kultuuri ja teaduse hübridiseerumisele, mis muudab nad tänapäeval üksteisest lahutamatuteks. Ta juhib tähelepanu maatriksitele, narratiivi tekstuurile, mida kasutab meedia võimalikest ohtudest ja katastroofidest rääkides. G. Mairali sõnutsi:

Seetõttu on narratiivi tekstuur kergelt teadusega pikitud, sealhulgas arvandmetega nagu temperatuur, mida saab täpselt mõõta, ning täpsete viidetega keemiale. Need ja teisedki omadused aitavad luua riskinarratiivide ajakirjanduslikku prototüüpi lausa sel määral, et ajakirjanduse allikad on otseselt seotud katastroofide ja epideemiate kirjeldustega, mille usutavuse alustalaks on teaduslik info (Mairal 2008).

\section{KOMEET LULIN}

11. juulil 2007. aastal avastas Quanzhi Ye Hiina Sun Yat-seni Ülikoolist Guangzhoust uue komeedi. Et ta töötas tookord Taivanil Lulini meeskonnas, siis nimetas ta omaleitud, Päikesest ja Maast suhteliselt kaugel paikneva ja ebatavalise orbiidiga komeedi Luliniks. Komeete on võrreldud tolmust ja jääst koosneva määrdunud lumepalliga, tuumale järgneb (harvem eelneb) gaasisaba. Sabalt peegelduv päikesevalgus jätab taevasse kauni värvilise jälje. Komeedisabade keemiline koostis varieerub. Lulini saba oli keemiliselt koostiselt sarnane komeet Halleyga, sisaldades tsüaani. 


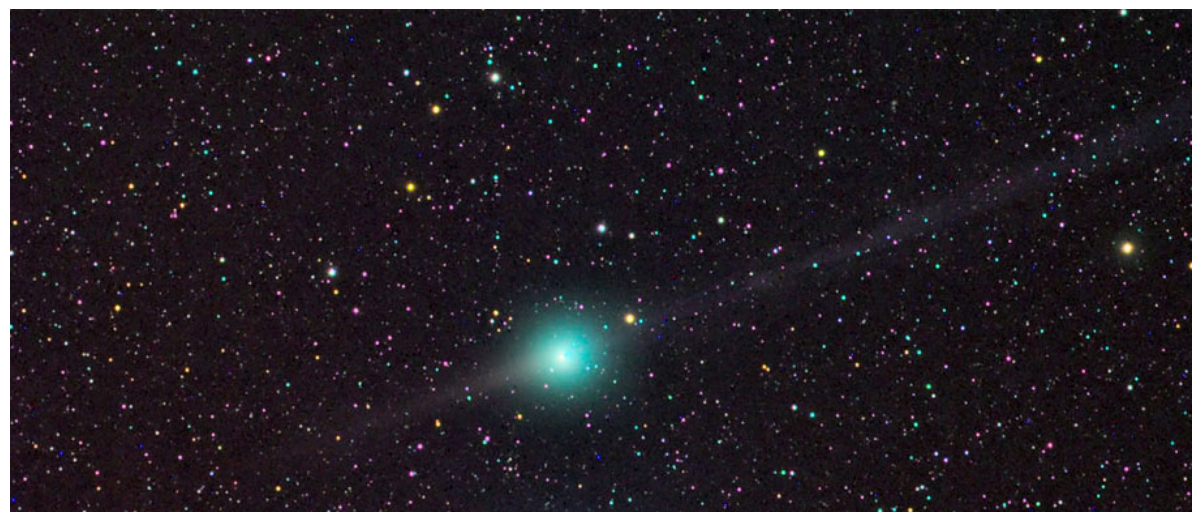

Foto: R. Ligustri (Talmassons, Italy) 2009. 6. veebruaril 11-cm refraktoriga ja STL11000 CCD kaameraga New Mexico (USA) teleskoobiga tehtud pilt.

Lulin muutus silmaga jälgitavaks alles 2009. aasta jaanuaris ja veebruaris, kuid algusest peale oli teada, et Lulin ei lähene Maale, vaid möödub sellest kaugelt.

Hale-Boppi komeedi avastaja Alan Hale kirjeldab komeet Lulini esimest nägemist 2007. aastal ja teavitab võimalusest jälgida seda 2009. aasta talvel: „Meie jaoks toimub komeet Lulini peamine etteaste pärast uue aasta algust, tegelikult muutub ta detsembri lõpus või jaanuari alguses hommikutaevas nähtavaks" (Hale 2007, 2009).

Uus komeet oli vaatlejate tähelepanu all juba 2008. aasta jooksul, loojanguvalguses lähenemise ajal. Vaatlejad arvutasid välja orbiidi, täpsustasid seda ja prognoosisid nähtavuse. Refereerides astronoomiateateid saame teada, et G. Marsden arvutas välja paraboolse orbiidi koos periheeliga $1,24 \mathrm{AU}$ jaanuarikuuks 2009. Komeet suurenes 2008. aasta viimastel kuudel, nii et ta magnituud oli umbes 11,0 juulikuu alguses, 10,5 augusti alguses, 10,0 septembri alguses ja 9,5 oktoobri alguses. Chris Wyatt Austraaliast nägi komeeti oma $25 \mathrm{~cm}$ reflektoriga 18. oktoobril. J. J. Gonzalez Hispaaniast nägi Lulinit 18. ja 19. oktoobril $25 \times 100$ pikksilmaga - komeedi altituud oli vaid 7-8 kraadi - ja määras tuuma diameetriks 4'. D. A. J. Seargent Austraaliast nägi komeeti 25x100 binokliga enne päikesega samaaegsust 27. oktoobril, määrates magnituudiks 8,1 ja tuuma diameetriks 5'. Üks järjepidevamaid vaatlejaid J. J. Gonzalez märkas 21. detsembril komeeti uuesti - Lulin oli 7 kraadi horisondist kõrgemal, tuuma läbimõõt oli 2.5'. 
Astronoomialeheküljed ja veebimeedia täpsustavad, et komeet Lulin möödub maakerast 24. veebruaril 2009 ja paikneb siis Maast 38 miljoni miili kaugusel ning on täiesti kahjutu. Ametlikud veebilehed annavad ka teada, et Lulini roheline värvus tuleneb gaasidest, mis moodustavad umbkaudu Jupiteri suuruses atmosfääri. Komeedituumast väljapaiskuvad gaasid sisaldasid tsüaani ja $\mathrm{C}_{2}$, mis mõlemad värvusid päikesekiirtes roheliseks (nt Phillips 2009). Komeeti sai vaadelda enne Päikese tõusmist lõunataeva suunas, ta oli nähtaval umbes kella kolme paiku öösel.

\section{HALLEY - MÜRGISE SABAGA KOMEET}

Erinevalt Lulinist on sajad komeedid olnud hästi vaadeldavad ja lähenenud pikemat aega Maale. Enamasti möödub sama komeet maakerast korduvalt, kuid tuhandeid aastaid kestev vaheaeg võimaldab inimkonnal neid kirjeldada vaid korra. Üks väljapaistvamaid komeete ilmus 1843. aastal ja möödus väga lähedalt Päikese pinnast. Kuna komeet oli ligi 60 korda heledam täiskuust ja päeval Päikese kõrval näha, siis levisid kuulujutud ja ennustused välgukiirusel. Näiteks ka Eestis põhjustas silmatorkav komeet maailmalõpu ennustusi. Komeedi saba pikkus ulatus ligi 300 miljoni kilomeetrini ehk kahe astronoomilise ühikuni. Erik Tago andmeil oli 1882. aastal taevas vaadeldav kõigi aegade kõige heledam komeet (Tago 1997). 1996. aasta talvel ilmunud Hyakutake ja aasta hiljem lähenenud Hale-Bopp olid mõlemad kaunid ja Eestis taevas pikka aega jälgitavad. Hale-Boppi komeedi ilmumise ajal sooritas Ameerika Ühendriikides massienesetapu prohvet Applewhite ja tema kogudus Heathenly Gate, pidades komeeti sõnumitoojaks, kelle taga läheneb kosmoselaev, mis viib usuühenduse liikmed vastu uuele ajastule. Usulahu liikmete ja prohveti motivatsioonid ja elukäik on tänaseni üks enamtõlgendatud teemasid religiooniantropoloogias, folkloristikas ja lähedastes valdkondades (nt Holliman 1998; Howard 2006; Kõiva 2007). Omal kombel oli see otsekui kaasaegne jätk varauusaegsetele arutlustele põrgu asukohast, mille näiteks tuntud teadlane ja oma ajastu mõtleja William Whiston paigutas komeedi pinnale (Jakapi 2005; Schechner 1997).

Umbkaudu sada aastat tagasi lähenes Maale taas Päikesesüsteemis tiirlev komeet Halley, mis külastab Maa lähikonda umbkaudu iga 76 aasta tagant ja on palja silmaga vaadeldav. Halley komeedi eripäraks on veel asjaolu, et seda võib näha vedamise korral kaks korda elu jooksul. Tuntud on näiteks seos Mark Twaini elukäiguga: ameerika kirjanik sündis täpselt kaks nädalat pärast komeedi periheeli ja suri 20. aprillil 1910, päev pärast Halley komeedi taasilmumist taevasse. Mark Twain kirjutab oma 1909 avaldatud autobiograafias: 
Ma tulin koos Halley komeediga 1835. aastal. See saabub uuesti järgmisel aastal ja ma kavatsen lahkuda koos temaga. Kui ma ei lahku samal ajal Halley komeediga, siis kujuneb sellest mu elu suurim pettumus. Kõikvõimas on kahtlemata lausunud: „Siin on need kaks äraarvamatut veidrikku, kes tulid koos ja peavad koos ka lahkuma“ (Litt 2009).

Selliseid seoseid inimese saatuse ja komeedi ilmumise vahel loodi sajandeid kometomantia abiga, mis tegeles komeetide ja riigivõimu, sh valitsejate tõusmise ja langemise, samuti nende tervise ja surma prognoosimisega. Kõrg- ja keskklassi huvisfääri teadmised jõudsid suuliselt, samuti kalendrite ja ajakirjanduse vahendusel ka ühiskonna lihtliikmeteni. Näiteks teated Napoleonile ennustatud sõjakaotusest huvitasid ja puudutasid talupojakultuuri lähedalt juba nekrutite saatuse tõttu, samuti oli aktuaalne teave sõdade ja valitsejate kohta.

Halley komeeti on kirjeldatud korduvalt alates aastast 240 e.m.a, babüloonia ja hiina taevavaatlejatest keskaja tuntud astronoomideni on kirjeldanud tema teekonna üksikasju ja komeedi enda väljanägemist. Alles 1705. aastal tuvastas inglise astronoom Edmond Halley, et sama komeet pöördub naaseb kindla perioodi järel, määras ilmumiste vahelise intervalli ja leidis samasuse erinevate ilmumiste vahel.

Just Halley komeediga seotud avastused ja raportid tema korduvast naasmisest ergutasid omaaegseid teadusarutlusi, aga ka kuulujutte mõeldavast Maa kokkupõrkest komeediga, aga ka komeedi kahjustavast mõjust inimkonnale ja elusolenditele. 1910. aastal möödus Halley nii lähedalt, et maakera liikus läbi komeedisaba. Paanika puhkes pärast seda, kui levisid teated, et muude ainete hulgas leidub sabas mürgist tsüaani. Paanika üks lahtipäästja oli fantaasiaküllane astronoom Nicolas Camille Flammarion (1842-1925), kes oli arvamusel, et kogu elu hävib komeedisaba mürgisuse tõttu. Et ta avaldas oma arvamust ka ajakirjanduses, levis nn õpetatud eksperthinnang välkkiirelt Euroopas ja Ameerikas. Rahvas hakkas ostma gaasimaske, spetsiaalselt müügile paisatud „antikomeedi tablette" ja komeedi eest kaitsvaid vihmavarjusid, et kuidagi kriitiline aeg üle elada (Strauss 2009). On osutatud, et paanikalaine tõttu kaevati endale varjulisi koopaid ja rajati varjendeid, osteti varuks hapnikku, meisterdati ise gaasimaske, et elada teistest veidikenegi kauem. On ka teateid enesetappudest, nt Ungaris, mis kaasnesid üldise Euroopa paanikahooga (Strauss 2009). Kollane ajakirjandus leiutas viise, kuidas lugu dramatiseerida ja muuta mõjukamaks, õhutades ka maailmalõpu hirme (Long 2009).

Halley mürgise sabaga seotud uudised ja kuulujutud, kogu paanikalaine tekkimises oli oma osa meedia informatsioonil ja õpetlaste poolt ajakir- 
janduses esitatud ekspertarvamustel. Gaspar Mairol (2008) viitab, et ookeanide vahelised reisid, ärikaalutlused ja lood katastroofidest ja epideemiatest olid modernse ajastu manifestatsioonid, samuti nagu seda on olnud teadusliku ja eksperthinnangu arenemislugu. Tema arvates oli 18. sajand aeg, mil eksperthinnangud levisid brošüüride, ajalehtede ja erinevate trükiste kaante vahelt narratiividena laiemasse avalikkusse, mis iseloomustab ka tänast massimeediat.

\section{RISKINARRATIIVIDE ARENGULOOST}

Gaspar Mairol on osutanud ajakirjandusstiilide ja jutustamisviisi arengule seoses katastroofide kajastamisega. Lissaboni maavärin, mis nõudis arvukalt ohvreid, Inglismaad 1703 rüüstanud orkaan, mis tappis üle 8000 inimese ja Londoni suur katk 1655 on jäädvustatud paljudes kirjandus- ja poolkirjanduslikes teostes. Katastroofide ja epideemiate kulgemist kirjeldava ajakirjanduse teerajajaks peab G. Mairol kirjanik Daniel Defoed, kes avaldas aasta pärast Inglismaad laastanud orkaani selle kohta juba aasta pärast raamatu. See oli erakordselt kiire ja vahetu reageerimine katastroofile. Tema kujutamisviisi iseloomustas maksimaalne lähedus kujutatud sündmustele, kohapeal võetud intervjuud ja sündmuse täpne kroonika, samas ka teatav dramatiseeritus, sensatsiooni loomine, et köita lugejate huvi. Neist võtetest kujunes siiani kasutatav ajakirjandusstiil, mis ühtlasi tugineb ka nn edastatud informatsiooni usaldusväärsuse kriteeriumile.

Kirjutades mõne aasta eest komeetide ja teiste tähistaevanähtustega korduvalt elustuvatest komeedihirmudest, -uskumustest ja -juttudest märkisin korduvuse kõrval seoseid tõsielunähtustega (Kõiva 2007), kuid ei osanud sõnastada nähtuse laiemat kandepinda. Antud juhul tundub võimalik adapteerida suuliselt levivale komeedifolkloorile (aga võibolla kogu usundilisele jutupärimusele) G. Mairoli nn riskinarratiivide maatriksi mõistet. Ohtudest ja riskidest rääkimise narratiivne maatriks on struktuur, mille abil hoiatatakse pandeemiate, maavärinate, liiklusõnnetuste jm eest, esitledes neid kui riskiolukordasid. Need narratiivimaatriksid võivad olla pikka aega latentselt varjul, kuni ilmuvad taas uutes oludes, mis neid esile kutsuvad.

1722. aastal avaldas D. Defoe romaani A Journal of the Plague Year (Katkuaasta žurnaal), kus ta kasutas uut narratiivset strateegiat, et anda teada mineviku kohutavatest sündmustest ja juhtida tähelepanu samasuguste sündmuste kordumise ohule. G. Mairali arvates oli D. Defoe teadlik enda kui ajakirjaniku mõjukusest ja oma eksperthinnangute väärtustatu- 
sest, mistõttu tema sõnum - katk võib korduda ja halvata Londoni - jõudis kiiresti kohale. Ta kasutas oma lapsepõlvemälestusi, mille vormistas osalt otsekui 1655. aasta katkulaastuse üleelanud kaupmehe memuaarid. Raamatukogudest ja arhiividest kogutud materjal täiendatuna isiklike mälestustega ja esitatuna esimese isiku narratiivina andis käsikirjale sügavuse. Niisiis kasutati uue riskantse sündmuse või selle võimalikkuse eest hoiatamiseks kirjeldusi eelmisest katastroofist, olulisel kohal olid realistlikkus, usaldusväärsus ja eksperthinnang, lool oli märgatav didaktiline suundumus.

\section{REAKTSIOONID LULINILE INTERNETIPORTAALIDES}

Kuigi nähtaval olemise aeg ega kaugus Maast ei soosinud Lulini mõju ühiskonnale ega avalikku tähelepanu, eelnesid Lulini taevasse ilmumisele ja jätkusid tema nähtava teekonna ajal trükimeedia ja internetiväljaannete informatiivsed uudised ja tutvustused, millele avalikkus reageeris veebikommentaaridega.

Kiire pilk Eesti populaarsesse internetiuudiste portaali kinnitas, et Lulinile reageeriti huumori, eneseiroonia ja poliitilise irooniaga kohe kui sai teatavaks tema ilmumine Eesti Vabariigi aastapäeval, 24. veebruaril. Aastapäeva tähistamise üle aasides luuakse allusioon roheliste mehikeste ehk ufonautidega, kes marsivad Eesti-Vene piiri ääres Narvas, alust humoristlikeks kommentaarideks annab komeedi värvus, mida viiakse seosesse riigilipuga, aga ka nn keskparteiga (internetikeeles kannab hüüdnime kesikud), kelle reklaamikampaania oluline sümbol oli müügile paisatud rohelise ristikulehega kaunistatud kohuke. Ka nimed on internetipäraselt kergelt moonutatud nagu Anzip Ansipi asemel.

Siinkohal mõned näited :

nujah, 17.02.2009 13:11

hea ajastus ..vabariigi aastapäevaks...roheline komeet lendab paraadi ajal üle vabaduse platsi (või üle Narva, vastavalt vajadusele suunatakse), kus mehed rohelistes vormides marsivad...peipsi-tagused vaatavad, et meie ka kosmoseriik.

ss, 17.02.2009 13:14

ja-jah tegelt on komeet sini-must-valge, lihtsalt kaugelt kosmosest alul paistab rohelisena

Em, 17.02.2009 13:35

Lahe, kui ta roheline on, siis huvitav mis ühenditest ta koos$n e b$ ? 
Loodusvarad lendavad ise meie lähedale, ei peagi neid ise kaevandama enam minema teistele planeetidele?

irf, 18.02.2009 00:18

See on kesikute [Keskerakonna - autori märkus] tervitus anzipile vabariigi aastapäevaks, Lulini roheline värv tuleb K-kohukeste reklaamplakatitest

Järgnevad naljatlused loovad allusioone kuulujuttudega Nibirust, hukutavast planeedist, mis põhjustavat maailmalõpu aastal 2012. Fantaasiad Nibiru ümber olid kitsamas ringis kestnud paar aastat, pälvides vähem tähelepanu kui 2012 maiade ennustuse järgi saabuv maailmalõpp. Teise teate stiil pole otseselt humoristlik, vaid pigem ettevaatusele manitsev, millele viitab vanem väljend „suu vett täis“ tähenduses 'vaikima, vait olema' ja nõue anda ellujäämisõpetusi. Järgnev musta huumori valdkonda kuuluv vastus - „tee endale lõpp, mis sa piinled“ loob allusioone anekdootidega, mis annavad nõu, kuidas käituda aatomipommi plahvatuse korral. Neljanda sisestusega tehakse taas pööre rohelise värvi suunas, mida nüüd seostatakse absurdse nakkavasse rohelusse kasvanud komeediga.

doktor, 17.02.2009 13:46

jah tegu on Nibulaga. Taevas on teda näha sellepärast ,et ta teeb maa orbiidi ümber (loe lennuvälja) ringe, et mitte kokku põrgata teiste taevakehadega. Täpselt sama moodi nagu lennukid teevad ringikujulisi tiire lennuvälja kohal. Kõigi eelduste kohaselt saab maandumistrajektoor vabaks 2012 talve aegu

From observatory, 17.02.2009 13:48

Kui Nibiru nii lähedalt mööduks, oleks kõikidel suu vett täis sõna otses mõttes. Kordan see pole naljarubriik siin, võtke asja tõsiselt ja paluks siia ellujäämisõpetused kirja panna punktide kaupa.

$\mathrm{Bb}, 17.02 .2009$ 13:53

observatooriumist, 17.02.2009 13:48

Soovitan lihtsalt endale kiire lõpu teha, mis sa ikka siin Nibiru käes piinled?

dr. känd, 17.02.2009 14:12

Rohelus tuleb sellest, et komeet on täiega rohtu kasvanud ja põõsaid täis.

NB! Kokkupuutel on nakkav, võite ise ka rohtu kasvada. 
Mõned kommenteerijad polnud uudist tähelepanelikult läbi lugenud ja üritasid saada komeedi kohta lisainformatsiooni, samas on pärimised vabas stiilis ja sisaldavad värvikamat sõnakasutust (kõõritama - 'viltu vaatama, piiluma, ka kõõrdi vaatama' siin tähenduses 'pingsalt, pidevalt vaatama'):

?, 17.02.2009 14:12

Mina tahaks teada, mis kell peaks binokliga kaema ja millises suunas? Terve päeva ei viitsiks taevasse kõoritada.

Samuti leidus paar ähmitsevat küsimust, kas ikka tõesti tsüaani sisaldav komeedisaba ei ole ohtlik, ehkki sellele küsimusele oli ametlik uudis juba vastanud.

Ingliskeelsetel astronoomiauudiste lehekülgedel ja muus meedias järgnesid uudisele enamasti konstruktiivsed hinnangud, kuigi seal leidus ka teistsugust suhtumist, sh üleskutseid käsitleda komeedi lähenemist kui märki, võtta seda tõsise lõpuaegade hoiatusena. Sarnaselt Eesti veebile meenutatakse vahel, et tegemist võib olla Nibiruga, ennustatud õnnetust toova planeediga. Toon on enamasti lõõpimisest kaugel. Näiteks vastab nime Sudhir kasutav isik 14. jaanuaril 2009 Jeremy Perezi asjalikule informatsioonile komeet Lulini liikumise kohta:

Tänud informatsiooni eest.

Kas tegemist on nibiruga?

Maa pooluse muutuse tõenäosus näib olevat väga suur?

Mis sa kostad?

Kena päeva!

Me seilame kõik samas paadis, mis siin enam valetada.

Nägemist

ilusaid unenägusid (Perez 2009)

\section{KOKKUVÕTE}

Teaduse ja kultuuri vaheline hübridisatsiooniprotsess iseloomustab tänapäevaseid riskinarratiive, kuid Gaspar Mairal osutab, et varasemad lood olid samasuguse ülesehitusega. Sage komeetide ilmumine elavdab uskumusjutte, paneb neid taasjutustama, tagab suulise leviku ja loomuliku variaabluse. Eestikeelne informatsioon Lulini kohta avaldati populaarse informatsiooniprotaali Delfi rubriigis „Teadus“. Ka kirjutise välislingid on teaduse-kesksed: Gary W. Kronki Cometography.com: C/2007 N3 (Lulin), Seiichi Joshida astronoomialehed: „Weekly Information about Bright Comets“ ja NASA teaduslehe informatsioon „Green Comet Approaches Earth“. 
Reaktsioonina uudisele kirjutati kommentaare komeedi mürgise saba kohta, mis jäi siiski kõrvalteemaks, erinevalt 1910. aastast, mil paanika muutis tegelikult käitumist, pannes inimesi uskuma, hankima kaitsevahendeid või koguni sooritama enesetappe. Hale Boppi komeet enesetapuajendina osutab samas, et lisaks hirmule komeedi ees on alati palju muid usu ja usaldusega seotud teemasid, mis suunavad enesehävitusele. Halley komeedi 1910. aasta ilmumise eel õhutas osa teadlasi tahtmatult paanikat, levitades enda meelest tõepärast informatsiooni ja andes avalikke eksperthinnanguid elu hävimisest maakeral komeedi mürgise saba tõttu. Seega oli paaniline käitumine otseseoses usaldusväärse informatsiooniga.

2009. aastal Maast kaugemalt mööduv komeet Lulin andis võimaluse sündmusele humoorikalt reageerida ja vabalt vaimutseda. Reaalset ohtu ei tajutud, katastroofi uskujaid oli vähe. Eestlased kasutasid vaimutsemiseks osalt riiklikku tähtpäeva, osalt võimalust eneseirooniaks, osalt võimalust poliitiliste parteide pilkamiseks, osalt naabripilkeks. Kaduvväike osa arendas mõne aasta eest populaarsuse võitnud maailma hävitava Nibiru teemat, millele üldiselt ei reageeritud ega hakatud teemat arendama.

Ingliskeelsete veebikommentaaride asjalikku poolt esindab Jeremy Perezi vastus Sudhirile Nibiru kohta:

Ma pole leidnud astronoomilisi tõendusi Sitchini pakutud planeet Nibiru kohta, aga kui eeldada korraks, et selline asustatud planeet tõepoolest eksisteerib, siis ma kahtlen, kas selle külgetõmbejõud saab olla nii väike, samas kui ta eraldab samapalju gaasi nagu muud tü̈̈pilised komeedid.

On märgatav, et kommentaaride kaudu tulevad esile kuulujutud sarnastest nähtustest, mis huvitavad lugejaid, nagu taevase katastroofi ended Nibiru näol. Suurima resonantsi tekitasid aastal 2009 hoopis maailmalõpuended seoses maiade muistses kalendris väidetavalt ennustatud maailmatsükli lõpust ja ühtlasi maailmalõpust aastal 2012.

Uurimistööd toetas ETF grant 8137. 


\section{KIRJANDUS}

Hale, Alan 2007, 2009. 432. Comet Lulin C/2007 N3. -Countdown to 500 Comets. Earthrise Institute. http://www.earthriseinstitute.org/coms43.html 7.12.2011.

Holliman, John 1998. Applewhite: From young overachiever to cult leader. $-C N N$, March 25, 1998. http://edition.cnn.com/SPECIALS/1998/hgate.review/ applewhite/ - 7.12.2011.

Howard, Robert Glenn 2006. Rhetoric of the Rejected Body at „Heaven's Gate“. Gender and Apocalyptic Desire. Millennialism \& Society 1. Toim Brasher, Brenda E. \& Quinby, Lee. London: Equinox Press, lk 145-164.

Jakapi, Roomet 2005. William Whiston, suur veeuputus ja kohutav spektaakel. Mäetagused 30, lk 9-16. http://www.folklore.ee/tagused/nr30/jakapi.pdf 7.12.2011

Kronk, Gary W. s.a. C/1843 D1. (Great March Comet). Gary W. Kronk's Cometography. http://cometography.com/lcomets/1843d1.html - 7.12.2011.

Kõiva, Mare 2007. Komeedid eesti rahvausundis. -Artikleid usundi-ja kombeloost. SATOR 6. Tartu: EKM Teaduskirjastus, lk. 161-197.

Litt, Doug 2009. Mark Twain's birthday. - Smithsonian Libraries. http:// smithsonianlibraries.si.edu/smithsonianlibraries/2009/11/mark-twainsbirthday.html - 07.12.2011.

Long, Tony 2009. May 19, 1910: Halley's Comet Brushes Earth With Its Tail. This day in Tech. Weired World. http://www.wired.com/thisdayintech/2009/ 05/dayintech_0519 - 07.12.2011.

Mairal, Gaspar 2008. A Narrative Structure of Risk in the Media. (Draft) TG04 „Sociology of Risk and Uncertainty“ - „First International Sociology Association Forum on „Sociology and Public Debate“. Barcelona, September 5-9 2008. http://www.riskanduncertainty.net/Gaspar_Mairal.pdf 07.12.2011.

Perez, Jeremy 2006. C/2007 N3 (Lulin) - JAN 9, 2009. - The belt of Venus. http:// www.perezmedia.net/beltofvenus/archives/001300.html - 07.12.2011.

Phillips, Tony 2009. Green Comet Approaches Earth. - Science \& NASA. Science News. http://science.nasa.gov/headlines/y2009/04feb_greencomet.htm 07.12.2011.

Renshaw, Steve \& Ihara, Saori 1996. The Tiger Tail Star Matasaburou and Comet C/ 1664 W1. http://www2.gol.com/users/stever/matasab.htm - 07.12.2011.

Schechner, Sara J. 1997. Comets, Popular Culture, and the Birth of Modern Cosmology. Princeton, New Jersey: Princeton University Press.

Strauss, Mark 2009. Ten Notable Apocalypses That (Obviously) Didn't Happen. Smithsonian.com. History \& Archaeology. http://www.smithsonianmag.com/ history-archaeology/Ten-Notable-Apocalypses-That-Obviously-DidntHappen.html - 07.12.2011.

Tago, Erik 1997. Sabatähed, mis tegid ajalugu. - Mäetagused 3, lk 53-56. http:// www.folklore.ee/tagused/nr2/kmt.htm - 07.12.2011. 


\section{Summary}

COMETS WITH POISONOUS TAILS, RISK NARRATIVES AND COMMENTS ONLINE

The hybridisation of culture and science has lead to the situation where the media and scientists' expert opinions both have an influence on how the society perceives a comet. The article compares the reflections of two comets: the Lulin comet from 2009 caused a wave of internet comments, and the Halley comet-inspired panic and risk narratives.

KEY WORDS: Halley comet, internet comments, comet panic, Lulin [comet], end of the world, risk narratives 